\title{
Editorial
}

\section{Industrial Compressor}

\author{
${ }^{1}$ Department of Mechanical Engineering, University of Wisconsin, Milwaukee, WI 53201, USA \\ ${ }^{2}$ Department of Mechanical Engineering, Michigan State University, East Lansing, MI 53201, USA \\ ${ }^{3}$ Department of Mechanical Engineering, University of Maryland, College Park, MD 20742, USA \\ ${ }^{4}$ Department of Energy Sciences, Lund University, Lund, Sweden \\ ${ }^{5}$ GE Aviation, Cincinnati, OH, USA
}

Ryoichi S. Amano, ${ }^{1}$ Abraham Engeda, ${ }^{2}$ Ashwani K. Gupta, ${ }^{3}$ Bengt Sunden, ${ }^{4}$ and Cheng Xu ${ }^{5}$

Correspondence should be addressed to Ryoichi S. Amano, amano@uwm.edu

Received 13 September 2012; Accepted 13 September 2012

Copyright () 2012 Ryoichi S. Amano et al. This is an open access article distributed under the Creative Commons Attribution License, which permits unrestricted use, distribution, and reproduction in any medium, provided the original work is properly cited.

This issue consists of five papers that deal with comprehensive studies on research and development of industrial compressors. Contributed papers deal with compressors used for low- and medium-pressure services in ethylene plants, lube oil plants, refineries, refrigeration, and air compression, as well as those used for high-pressure services, such as those used in ammonia, urea, and methanol synthesis, refinery recycle, and natural gas compression and injection. Some also deal with pipeline compressors that are of low- and medium-pressure ratios used in wide range of applications, while other compressors are used in recycle services such as those used in methanol plants, ethylene oxide plants.

Papers presented this special issue cover topics extending from design experience to detailed design feature studies and include cover broad range of compressors: axial compressor, centrifugal compressor, and reciprocating compressor. There are many interesting topics and studies. It is expected that the knowledge and experiences presented in both academic and industrial readers will benefit from this special issue.

The papers included here are: "A novel approach to evaluate the benefits of casing treatment in axial compressors" by G. Legras et al., "Performance improvement of a centrifugal compressor by passive means" by N. Sitaram and S. M. Swanmy, "Meridional considerations of the centrifugal compressor development" by C. Xu and R. S. Amano, "Reciprocating compressor 1D thermofluid dynamic simulation: problems and comparison with experimental data" by A. Gimelli et al., and "Empirical design considerations for industrial centrifugal compressors" by C. Xu and R. S. Amano. It is expected that the information provided here on the specific types of compressors will provide useful information to wide readership from academia and industry.

Ryoichi S. Amano Abraham Engeda Ashwani K. Gupta Bengt Sunden Cheng Xu 

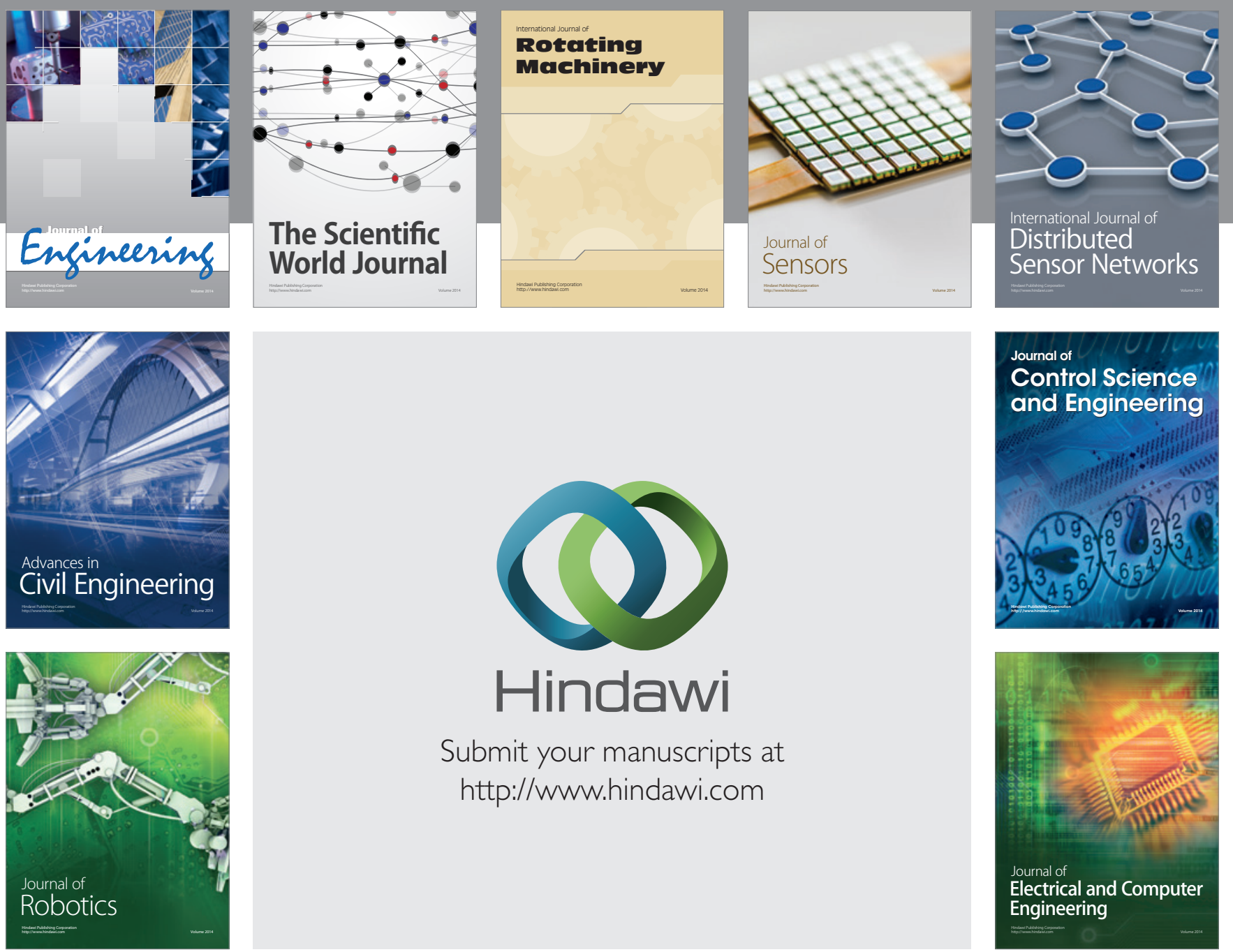

Submit your manuscripts at

http://www.hindawi.com
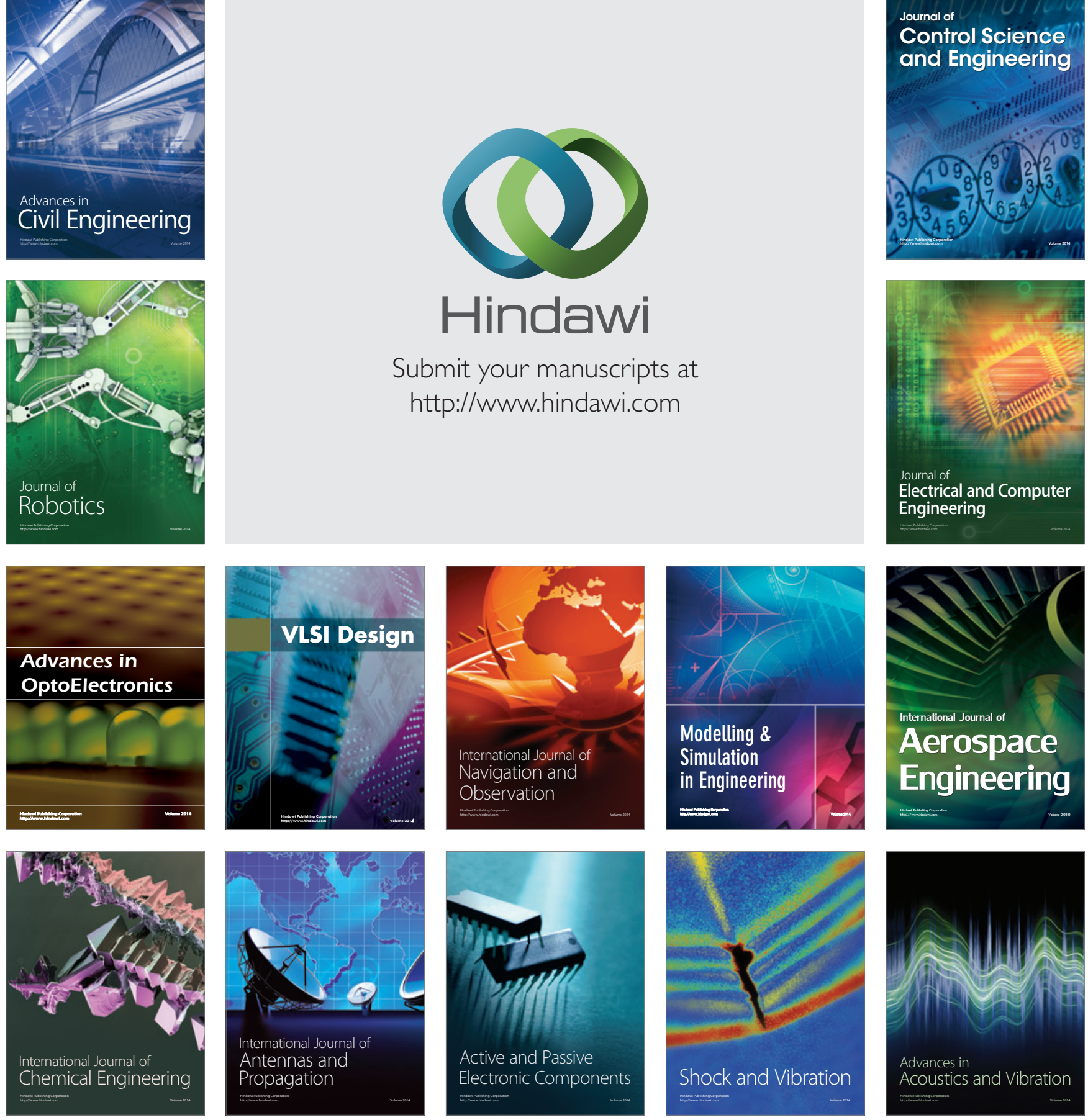